\title{
PROPOSTA DE IMPLEMENTAÇÃO DA FERRAMENTA PDCA PARA MAXIMIZAR OS RESULTADOS DA GESTÃO DOS ESTOQUES: ESTUDO DE CASO NA EMPRESA CALOI
}

\section{ARTIGO ORIGINAL}

SANTOS, Larissa Peixoto dos ${ }^{1}$, ALVES, Alcibialdina Silva ${ }^{2}$, NUNES, Laryssa Karen Ribeiro ${ }^{3}$, RAMOS, Jose Manoel ${ }^{4}$, ROBERTO, José Carlos Alves ${ }^{5}$

SANTOS, Larissa Peixoto dos. Et al. Proposta de implementação da ferramenta PDCA para maximizar os resultados da gestão dos estoques: estudo de caso na empresa Caloi. Revista Científica Multidisciplinar Núcleo do Conhecimento. Ano 06, Ed. 05, Vol. 08, pp. 194-217. Maio de 2021. ISSN: 2448-0959, Link de acesso: https://www.nucleodoconhecimento.com.br/administracao/pdca-para-maximizar, DOI: 10.32749/nucleodoconhecimento.com.br/administracao/pdca-para-maximizar

\section{RESUMO}

O presente estudo de caso tem como finalidade identificar e compreender os canais de distribuição e controle de estoque a partir da ferramenta PDCA, usando o $5 \mathrm{~W} 2 \mathrm{H}$ para auxiliar a empresa no entendimento de suas fragilidades, verificar a qualidade das operações e como a ferramenta contribui para a melhoria dos processos.

\footnotetext{
${ }^{1}$ Graduando em administração.

${ }^{2}$ Graduando em Administração.

${ }^{3}$ Graduando em Administração.

${ }^{4}$ Coorientador. Especialista MBA, docente em pós-graduação e graduação.

${ }^{5}$ Orientador. Mestrado profissional em Engenharia de produção. Especialização em Gestão em Logística empresarial. Graduação em Administração com Ênfase em Marketing.
}

RC: 85120

Disponível em: https://www.nucleodoconhecimento.com.br/administracao/pdca-paramaximizar 
Atualmente, as empresas estão sempre em busca de melhores resultados, pois devem estar sempre atentas aos detalhes importantes de sua gestão, um dos quais é a gestão e controle de estoque. Os gestores devem avaliar o melhor método de abastecimento de estoque para evitar o risco de muitos produtos, existem várias ferramentas que podem ajudar neste gerenciamento. $O$ objetivo deste trabalho é um estudo de caso que contém um método de implementação do uso de ferramentas PDCA para melhorar o processo de controle de estoque. $O$ artigo foi produzido através de pesquisas na organização e em áreas funcionais, o ponto-chave nessas áreas é a operação, e a falta de controle de estoque, que é um problema de destaque. Quanto a metodologia utilizou-se de pesquisa qualitativa, que é realizada por meio de coleta de dados, entrevistas, análise de documentos e dados por meio de questionários. Posteriormente, através da utilização do método PDCA, aliado à aplicação das ferramentas da qualidade $5 \mathrm{~W} 2 \mathrm{H}$, foi apresentada uma proposta de melhoria detalhada para redução dos erros de estoque, ferramenta que pode melhorar significativamente o processo produtivo.

Palavras-Chave: PDCA, Estoque, Qualidade.

\section{INTRODUÇÃO}

Nos últimos anos, poucas áreas da administração de empresas mudaram tanto como a logística. Há muito tempo a sociedade pede por melhorias na qualidade, no processo, no atendimento, no produto ou até mesmo no serviço.

O ciclo PDCA é uma ferramenta de gestão desenvolvida para melhorar e controlar continuamente os processos e produtos, o ciclo aplicável na gestão da qualidade proposto por Waltera Shewhart em 1930 também é chamado de ciclo de Shewhart ou ciclo de Deming, mas foi somente na década de 1950 que o ciclo PDCA se 
tornou amplamente conhecido no mundo através de William Edwards Deming e seu discurso no Japão.

Diversas ferramentas vêm se aperfeiçoando no mercado, uma delas foi o PDCA, implementação desse trabalho. O objetivo desse trabalho é a implementação da ferramenta PDCA no processo logístico da empresa para que venha apresentar melhorias no processo de entradas e saídas de materiais auxiliares do estoque.

Para a empresa que implicam cruzar linhas funcionais as análises mais complexas ou decisões importantes passaram a ser um exercício muito arriscado e constantemente evitado. Esses conflitos podem ser solucionados com a identificação de aplicação de modelos mais articulados de gestão, que possibilitem uma participação dos funcionários mais intensa com ideias e ações no desenvolvimento do trabalho. (SILVA 2012, p. 16).

Na parte teórica foram apresentadas as técnicas utilizadas e as informações para a implementação do método PDCA e seus gerenciamentos, ele é utilizado para analisar os riscos dos processos, prevenir os erros e identificar os problemas facilitando a ação para eliminá-los.

Este trabalho visa compreender e explicar um método considerado muito importante para a gestão da qualidade, o ciclo PDCA, esse método é um processo cíclico composto por quatro etapas, nas quais serão utilizadas ferramentas da qualidade para obter informações ou aplicar operações na organização.

O projeto fará recomendações de pesquisas para resolver falhas no estoque com base no uso de ferramentas $5 \mathrm{~W} 2 \mathrm{H}$, podendo identificar outras questões que podem afetar o estoque total e apresentar recomendações para a implementação de um plano de ação para identificar a causa do problema e resolvê-lo.

RC: 85120

Disponível em: https://www.nucleodoconhecimento.com.br/administracao/pdca-paramaximizar 


\section{REVISÃO BIBLIOGRÁFICA}

A revisão bibliográfica é a execução da pesquisa de acordo com as obras de autores que de forma retrata o tema abordado, de acordo com as normas científicas da ABNT, confirmam o conteúdo exposto e a cientificidade do conteúdo explicado com base nas informações absorvidas.

\subsection{CONCEITOS DE LOGÍSTICA}

Logística é uma operação integrada para cuidar de suprimentos e distribuição de produtos de forma racionalizada, o que significa planejar, coordenar e executar todo o processo, visando a redução de custos e ao aumento da competitividade da empresa.

Segundo o Council of Logistics Management, a palavra logística pode ser determinada como: implementação e o controle eficientemente do custo correto, o processo de planejar, estoques durante a produção, o fluxo e armazenagem de matérias-primas, produtos acabados, e informações referente a essas atividades, desde o ponto de origem até o ponto de consumo, com o intuito de atender os requisitos do cliente.

\footnotetext{
A logística faz-se presente em todos os momentos sejam eles profissionais ou pessoais: armazenando, transportando, distribuindo objetos, recursos, informações, suprimentos, produtos acabados, semiacabados, matérias-primas, um simples e-mail ou telefonema. Todas as áreas de uma empresa têm suas metas e fases a serem desenvolvidas e a logística permite o desenvolvimento de todas elas, mesmo que se faça despercebida ela está em cada momento, em cada ação. Cabe às áreas estudar como utilizar-se das ferramentas que a logística oferece e como ela interfere nos seus resultados. (FERNANDES, 2012, p.11)
}

A logística tem como produto a ser comercializado o serviço. As metas e desafios a serem atingidos restringem-se à perfeição de suas atividades. Se um material

RC: 85120

Disponível em: https://www.nucleodoconhecimento.com.br/administracao/pdca-paramaximizar 
específico não estiver disponível quando é preciso para a produção ou consumo, isso pode acarretar a perda de um consumidor ou a paralisação de uma fábrica, por exemplo. A vista dessa situação o seu concorrente descobre uma chance para efetuar o que o seu produto não atingiu. Todos esperam da logística eficácia e eficiência para com os seus produtos.

A logística será considerada eficiente somente quando apresentar a capacidade de disponibilizar recursos e bens, demonstrando com eficiência que é possível alcançar os resultados desejados pela empresa, porém não basta apenas conseguir efetuar a aquisição seguida de posterior entrega e armazenagem. O resultado esperado é que em todas as etapas a logística demonstre sua eficácia, fazendo as tarefas, mas a todo momento com segurança, qualidade e pontualidade. O consumidor quer receber o produto na hora marcada e sem defeitos ou avarias e não apenas receber seu produto. (SANTOS, 2012, p. 15).

\subsection{GESTÃO DE ESTOQUE}

Para (KUEHNE, 2002, p. 19) a gestão econômica dos estoques é resumidamente o ato de gerenciar recursos possuidores de valor econômico e atribuído ao suprimento das necessidades futuras de material, nesta organização. objetiva, portanto, em uma primeira abordagem, preservar estoques em frequente equilíbrio em associação ao nível econômico ótimo dos investimentos e isto é conseguido, armazenar estoques mínimos, sem ter o risco de não os ter em quantidades suficientes e necessárias para manter o fluxo de produção da encomenda em equilíbrio com o fluxo de consumo.

Portanto, o estoque não é apenas os produtos armazenados no armazém, mas também os produtos expostos nas prateleiras expostas aos consumidores. $O$ surgimento da gestão de estoque deve-se à necessidade de controlar todos os bens

RC: 85120

Disponível em: https://www.nucleodoconhecimento.com.br/administracao/pdca-paramaximizar 
que entram por meio da compra de produtos de diferentes segmentos de mercado, pois serão vendidos diretamente ao consumidor (o que é considerado estoque).

A gestão de estoques está relacionada ao processo de decisão sobre quais materiais farão parte do estoque da empresa, suas quantidades, escolha do método sobre o momento e as quantidades de ressuprimento. Ela também é responsável por algumas atividades operacionais, tais como o registro de movimentações de entradas e saídas de materiais, conhecimento sobre o estado do estoque, administração de itens segregados na quarentena, nível de estoque e controle de inventários a realizar. Possui interface direta com a direção da empresa, departamento de compras, marketing e departamento de produção. (BRITO e SPEJORIM, 2012, p. 211).

Os estoques são acúmulos de matérias-primas, insumos, componentes, produtos em processo e produtos finalizados que aparecem em inúmeros pontos por todos os canais logísticos e de produção na empresa

O funcionamento administrativo de uma empresa refere-se a todas as atividades de armazenagem e movimentação, visando a facilitação do sistema de circulação de produto desde a aquisição da matéria prima até a entrega do produto ao consumidor final. Quando relacionados aos fluxos de informação que possuem o papel de ajudar na decisão sobre a movimentação dos produtos e transportes, tendem a ter aumento sobre os níveis de serviço prestados (BALLOU, 2012).

A empresa tem como principal objetivo minimizar custos e aumentar a lucratividade, sendo assim, analisar minuciosamente cada processo é essencial para alcançar resultados e metas definidas. Tendo em vista, o encolhimento de capital para consumo, a gestão de estoques deve receber atenção especial.

\subsection{TIPO DE ESTOQUE}

O processo de gestão de estoques pode ser decomposto em quatro aspectos básicos: as questões organizacionais envolvidas, as políticas e modelos

RC: 85120

Disponível em: https://www.nucleodoconhecimento.com.br/administracao/pdca-para$\underline{\text { maximizar }}$ 
quantitativos utilizados, o tipo de tecnologia usada e, finalmente, a monitoração do desempenho do processo.

$\mathrm{Na}$ determinação dos níveis de estoques é importante ressaltar dois fatores: Quanto maior a quantidade estocada, maiores serão os custos com a manutenção dos estoques, todavia representa garantia contra a paralisação da empresa por falta de material. A diminuição das quantidades em estoque, reduz os custos de estocagem, entretanto, os custos de obtenção dos materiais aumentam e tem a possibilidade de ocasionar a paralisação das atividades da empresa pela falta de material. (KUEHNE, 2002, p. 19)

Existem muitos modos de classificar os estoques, uma delas, e constantemente usada, estabelece relação ao fluxo de material que entra em uma organização industrial, passa pela mesma e sai. Pode ser conceituado como:

Matérias-primas: são itens comprados e recebidos que não entraram no processo de produção ainda, envolvem material comprado, subconjuntos e peças componentes.

Produtos em processo: matérias-primas que esperam para entrar em operação ou já entraram no processo e estão em operação.

Produtos acabados: os produtos finalizados do processo de produção que estão preparados para serem vendidos como itens acabados. Podem ser retidos no depósito central ou fábrica, ainda, em vários pontos do sistema de entrega.

Estoques de distribuição: produtos que são localizados no sistema de distribuição quando acabados.

Suprimentos de manutenção, de operação e de reparo: itens utilizados na produção que não se tornam partes do produto. Incluem peças sobressalentes, lubrificantes, material de limpeza e ferramentas manuais.

RC: 85120

Disponível em: https://www.nucleodoconhecimento.com.br/administracao/pdca-paramaximizar 
Destaca-se também, procedimentos que são utilizados também na avaliação de estoques, por exemplo: FIFO (First In, First Out) ou PEPS (Primeiro que entra, Primeiro que sai) - é seguida uma ordem lógica desse método de controle de estoque, o primeiro objeto armazenado para estoque é o primeiro que sai

O controle realizado é feito pela data de entrada do lote, enviando ao sistema de dados do tipo fila. Esse mecanismo é muito usado, visto que realiza um fluxo natural, indicado para indústrias eletrônicas e alimentícias.

FIFO (First-Expire, First-Out) - modo usado em empresas que estocam mercadorias com data curta de vencimento, esse método busca classificar a saída dos itens pelo seu vencimento. A ferramenta é um avanço do FIFO, entretanto, sendo muito incomum. Esse modo é empregado nos setores farmacêutico, hospitalares e alímenticia, onde é possível envolver o desaproveitamento dos materiais vencidos retirando do estoque antes da expiração da data de vencimento

LIFO (Last-in, First-out) ou UEPS (Último a entrar, primeiro a sair) - técnica que consiste em tirar primeiro do estoque o último item que entra. $\mathrm{O}$ pronunciamento técnico CPC 16Esse não aceita esse método. Desta maneira, o LIFO não é recomendado para estoques que mostram um giro muito extenso, em razão de que existe o perigo dos itens estocados passar o prazo de validade ou danificarem, protegendo as perdas para a empresa, geralmente utilizado em produtos que tenha uma durabilidade maior e não vencem.

Segundo Viana (2000): Qualquer método que seja, é essencial a plena observação das rotinas em prática com o objetivo de evitar problemas de controle, com consequências no inventário, que resultam em prejuízos para a empresa, Comando de estoque é o procedimento praticado para fiscalizar, gerir e registrar, a saída e entrada de mercadorias e produtos seja no comércio ou em uma indústria 
Tanto as matérias-primas quanto os bens produzidos devem usar o controle de estoque. O primeiro passo para alcançar um bom controle de estoque é ter um bom e confiável sistema que auxilie a gerenciar todos os materiais.

\subsection{IMPLEMENTAÇÃO DO PDCA}

Seguindo o conceito de Mattos (2010, p. 40 - 41)

o método PDCA trata didaticamente o processo de melhoria contínua como uma sequência de três passos em um ciclo: aproveitado o máximo dos dados disponíveis para seu desenvolvimento sendo eles de equipes, de orçamento, planos de atuação, tendo a certeza de um planejamento como um compromisso geral e não como missão de uma área técnica; procurando uma execução de uma obra como planejamento, pois nem sempre seu cronograma de obras tem seus objetivos alcançados, tornando necessária uma nova aferição do que foi realizado.

Dessa forma, os índices de campo podem ser apropriados, como a propriedade das equipes, considerando os seus desvios referentes a seu planejamento e, por fim, revisando o mesmo, dando a ele um novo direcionamento, a fim de que o gerente coloque sua obra de volta ao eixo.

A implantação da qualidade total, em qualquer segmento, só é possível através do desenvolvimento de métodos e técnicas que demonstrem um grande auxílio que a qualidade traz à organização. Cada caso da implementação de sistema de qualidade deve ser um processo observado.

Cada organização tem suas próprias características, e o sistema deve se adequar ao ambiente disponível.

O PDCA é uma ferramenta de qualidade utilizada no controle de processos, que tem como foco a solução de problemas. Ele é composto por quatro fases, divididas em:

RC: 85120

Disponível em: https://www.nucleodoconhecimento.com.br/administracao/pdca-paramaximizar 
1. Planejamento (P) - Essa etapa consiste em:

- Estabelecer metas.

- Estabeleça métodos para atingir os objetivos propostos.

2. Execução (D)

Executar as tarefas exatamente como esperado na fase de planejamento e coletar dados que serão usados na próxima fase de verificação do processo. $\mathrm{Na}$ fase de implementação, a educação e a formação no trabalho são de extrema importância.

3. Verificação (C)

A partir dos dados coletados durante a execução, comparar os resultados alcançados com as metas planejadas.

4. Atuação Corretiva (A) - Essa etapa consiste em atuar no processo em função dos resultados obtidos. Existem duas formas de atuação possíveis:

- Se a meta for alcançada, use o plano proposto como padrão.

- Se o plano não for eficaz, tome medidas para justificar o não cumprimento da meta.

Destaca-se no ambiente organizacional como um método gerencial para melhoria de processos e soluções de problemas, sendo a base da melhoria contínua, podendo ser utilizado em qualquer tipo de entidade, seja ela em uma empresa privada, uma organização sem fins lucrativos ou em um setor público.

De acordo com Campos (2004), o PDCA de melhoria é empregado para atingir metas de formas contínuas e para solucionar problemas, este método tem 8 etapas, Que são compostas pela: análise do processo, observação do problema, 
identificação do problema, plano de ação, verificação, ação, padronização e conclusão. Para ajudar o procedimento as ferramentas são usadas conforme a complexidade do problema, tendo variações de ferramentas básicas até avançadas

O PDCA é usado principalmente em padrões de sistema de gestão e pode ser usado em qualquer organização criada para garantir o sucesso do negócio, independentemente da sua área ou departamento (vendas, compras, engenharia etc.).

\subsection{JUST IN TIME}

O Just-in-time é um planejamento de reorganização do ambiente produtivo no entendimento ordenado de que a eliminação de desperdícios, visa o contínuo melhoramento dos processos de produção, é a base para o melhoramento da posição competitiva de uma empresa, em particular no que se referem os fatores com a velocidade, a qualidade e o preço dos produtos.

Dizia (CAXITO, 2012, p. 112), que para melhor entender o foco do sistema Justin Time na redução dos custos, é preciso entender de forma geral como são classificados os custos em uma empresa.

A contabilidade de custos (área da contabilidade que lida com o entendimento e gestão dos custos) divide em duas categorias: os custos fixos e as variáveis.

Os custos fixos são aqueles ligados à infraestrutura da organização, como edificações, mão de obra indireta, setores não diretamente envolvidos na atividade de produção, equipamentos e outros.

Os custos variáveis são todos aqueles ligados diretamente à produção da empresa: matéria-prima, materiais intermediários, mão de obra direta, a energia gasta nos

RC: 85120

Disponível em: https://www.nucleodoconhecimento.com.br/administracao/pdca-paramaximizar 
equipamentos etc. O resultado da soma dos custos fixos com os custos variáveis nos dá o custo total.

Em comparação com os sistemas de produção tradicionais, os sistemas JIT têm várias diferenças nos métodos, dependendo da demanda, talvez a principal característica seja "puxar" a produção durante o processo de produção, nesse sistema ("puxar"), o material é processado em uma operação apenas quando as operações subsequentes do processo assim o exigirem, e o material envia um sinal ao fornecedor quando necessário (sua função é "ordem de produção") à operação, que aciona a produção e o fornecimento, se nenhum sinal for enviado, nenhuma operação é acionada; os sistemas tradicionais são sistemas que "empurram" a produção desde a compra de matérias-primas e componentes até o estoque de produtos acabados. Nesse caso, as operações são disparadas por três condições: 1)Pela disponibilidade de materiais e componentes a processar; 2) Pela disponibilidade dos recursos necessários; e 3) Pela existência de uma ordem de produção, formada por algum sistema concentrado que, a partir de previsões de demanda, criou programas de produção com base em estruturas dos produtos.

Ao discorrer acerca do processo JIT, Laugeni (2002, p. 306), também tem como enfatização de que: O sistema JIT aborda problemas que são tratados através das técnicas de solução de problemas/melhoria, no processo de procura de soluções, devem ser introduzidos todos os colaboradores, apesar seu nível hierárquico, esse processo não tem final, devendo ser sempre melhorado pela empresa, sendo uma melhoria constante, ou Kaizen.

O objetivo do Just in Time é produzir bens e serviços exatamente quando são necessários, não antes para que não formem estoques, e não depois para que seus clientes não tenham que esperar. Podemos adicionar no Just in Time os requisitos de qualidade e eficiência. O sistema Just in Time tem como objetivo fundamental à 
melhoria contínua do processo produtivo. A perseguição destes objetivos dá-se, por meio de um mecanismo de redução dos estoques, os quais tendem a camuflar problemas.

A meta do Just In Time é retirar função secundária no sistema de manufatura que traga custos indiretos seja ela qual for, que não some valor para a empresa, que impossibilite uma produtividade melhor ou agregue despesas desnecessárias no sistema operacional do cliente.

\subsection{IMPORTÂNCIA DO SISTEMA MRP}

Segundo Correa (2000) o objetivo dos sistemas MRP é Ajudar a produção, comprar apenas o essencial e só em momentos crucial, ou seja, na última ocasião, pretendendo que os estoques sejam eliminados, produzindo uma sequência de encontros marcados entre componentes de um mesmo nível, para operações de montagem ou fabricação e atualmente o mercado tem contado com várias empresas que contribuem com softwares que se adequam a diversos tamanhos de empresas, e de fácil manuseio.

A sistematização é simples, mas requer que o administrador dê uma introdução detalhada ao processo de produção para garantir que as informações sejam obtidas, do ponto de vista do mercado nacional atual, a quantidade de uso é grande e o estoque não é necessário e pode até prejudicar a liquidez da empresa, portanto, para o estoque mínimo, uma análise criteriosa do tempo de recebimento da mercadoria de cada fornecedor é essencial para o estoque.

Conforme Slack et al. (1996) apud Souza (2003), o MRP (Material Requeriments Planning), isto é, o cálculo das necessidades de material, teve surgimento na década de 60 com a finalidade de ajudar as empresas no cálculo da quantidade de um produto específico, e em que ocasião deveria ser feito tal quantia.

RC: 85120

Disponível em: https://www.nucleodoconhecimento.com.br/administracao/pdca-paramaximizar 
O MRP está entre um dos três principais sistemas de Planejamento e Controle da Produção (PCP), juntamente com Just in Time (JIT) e Optimized Production Technology (OPT). Com objetivo de ajudar a produzir e comprar apenas o necessário e apenas no momento necessário, visando a eliminação de estoque.

A função do MRP é dar suporte sobre a decisão da quantidade e o momento do deslocamento de materiais em condições de serviços e demanda, a prática tem demonstrado que um bom MRP pode moderar os níveis dos estoques, dando liberdade a capital de giro e espaço físico, dando possibilidade a implementação de novas linhas de produção com estes meios, formando um círculo virtuoso: aumento da capacidade de produção, aumento dos lucros, maior capacidade de investimento redução dos níveis de estoques.

Nele as empresas que alcançam determinado tipo de componente através de um programa que mostra os componentes imposto para cada nível de montagem e com base nos seu lead times, calculando o quanto, e quando desses itens são precisos.

Para isso, realiza-se à necessidade de analisar a natureza desta demanda de componentes, esta demanda pode ser dependente e independente, para explicar este conceito se pode utilizar o exemplo de uma fábrica de canetas esferográficas onde a caneta montada identifica-se como uma demanda independente, por se atuar de um produto pronto para venda e sua tampa como demanda dependente, em razão de provocar sua necessidade no decorrer da demanda da caneta montada no caso o produto.

Uma das principais vantagens do MRP é a sua natureza dinâmica, é um sistema que reage bastante bem às mudanças, esta é uma condição que se torna mais importante a cada dia, num ambiente competitivo que é cada vez mais turbulento. 


\section{MATERIAIS E MÉTODOS}

Metodologia é um conjunto de abordagens, técnicas e processos utilizados pela ciência para formular e resolver problemas de aquisição objetiva do conhecimento, de uma maneira sistemática.

o método científico pode ser definido como um conjunto de regras básicas empregadas em uma investigação científica, com o objetivo de obter resultados, de forma imparcial e confiável, entretanto este projeto apresentará diferentes ferramentas e métodos que vai auxiliar a identificar as soluções da Caloi Norte S/A (LIBÓRIO e TERRA, 2015, p. 15).

Finalmente, é importante definir o que representa um problema segundo o conceito do controle da qualidade total. Um problema é o resultado indesejável de um processo, ou seja, é um item de controle que não atinge o nível desejado.

\subsection{PROCEDIMENTOS METODOLÓGICOS}

Os procedimentos metodológicos são as classificações da pesquisa com intuito de definir os métodos e formas a serem utilizadas nesse processo de estudo.

Esta pesquisa é caracterizada quando os pesquisadores e os participantes representativos da situação ou do problema estão envolvidos de modo cooperativo ou participativo. Foi implementado melhorias no sistema SAP, a automação dos processos de apontamento, a acuracidade dos produtos auxiliares da produção sistemática, e o ressuprimento de materiais.

Devido à enorme competitividade entre empresas do ramo supermercadista, temos a necessidade de implantação de controles e gerenciamentos mais eficazes, neste 
momento da atualidade o aumento da competitividade é devido às mudanças no comportamento dos consumidores. (KAWASE e DE PAULA, 2012).

Em uma empresa o estoque pode ser considerado um dos maiores desafios na hora de fazer sua gestão, sendo que é de suma importância que seja tratado como um órgão vital para o bom funcionamento e a permanência em longo prazo da empresa no mercado.

\subsubsection{QUANTO À NATUREZA}

A natureza da pesquisa diz respeito à finalidade, a contribuição que ela trará a empresa. Devido aos fins para ampliar uma área de conhecimento, essa pesquisa se adequa a natureza básica, foi realizada uma pesquisa quali-quantitativa, de acordo com os quadros com perguntas por aéreas da referida empresa, obtendo uma porcentagem de problemas na área da logística da empresa Caloi Norte S/A.

A pesquisa qualitativa, de acordo com Malhotra et al. (2005), é adequada quando enfrenta-se um contexto de incerteza, pois os resultados podem mudar o julgamento e também se afastar das expectativas

Os dados coletados são para mostrar problemas metodológico prováveis, que não estão esclarecidos quanto ao problema de pesquisa, o método é menos estruturado, porém mais intensivo que as entrevistas por meio de questionários.

A pesquisa pode ser qualificada como qualitativa quando são observados os métodos de controle de estoque que podem interferir diretamente na gestão de estoque adequada, a forma como são armazenados as mercadorias e o layout da fábrica são observados durante o estudo.

RC: 85120

Disponível em: https://www.nucleodoconhecimento.com.br/administracao/pdca-paramaximizar 
Para Prodanov e Freitas (2013, p. 43), pesquisa científica é a efetuação de um estudo idealizado, que tem sido o método de abordagem do problema, o que define o aspecto científico da investigação, o seu objetivo é de encontrar respostas para perguntas por meio da utilização do método científico.

\subsubsection{QUANTO AOS FINS}

Quanto aos fins foi realizada a pesquisa descritiva, pois expõe características claras e delineadas, desenvolvendo técnicas bem estruturadas a partir da sua coleta de dados.

Segundo Prodanov e Freitas (2013, p. 127), "expõe as características de uma determinada população ou fenômeno, demandando técnicas padronizadas de coleta de dados".

Dizia Vergara (2016, p. 74), a pesquisa descritiva exibe características de um determinado fenômeno, ou determinada população, determinando também correlações entre fatores e definir sua natureza, não tem compromisso de esclarecer os fenômenos que descreve, apesar de, servir de base para tal explicação.

Por outro lado, a pesquisa descritiva é algo que promove a fronteira do conhecimento e confirma ou refuta coisas que podem já existir. A tecnologia que a implementa pode ser usada para fornecer caminhos possíveis, e os pesquisadores devem traçar esses caminhos para coletar, organizar e analisar as informações a fim de tirar conclusões. Ao escolher o método adequado, a eficácia pode ser atribuída à conclusão, garantindo assim que o novo conhecimento tenha uma base sólida.

RC: 85120

Disponível em: https://www.nucleodoconhecimento.com.br/administracao/pdca-paramaximizar 


\subsubsection{QUANTO AOS MEIOS}

Segundo Lakatos e Marconi (2000, p. 107), as táticas de dados coletados é um conjunto de processos ou preceitos de que se serve uma ciência, sendo também, as habilidades para usar normas ou preceitos, no alcance de 126 de suas utilidades, correspondem, por conseguinte, à parte prática do conteúdo recolhido e observado.

Quanto aos meios foi baseado em uma pesquisa documental, através de coletas de dados realizadas com os gestores e diretor da empresa Caloi Norte S/A, através de entrevistas e do acesso ao banco de dados, das observações realizadas no dia da visita, para juntar todas as informações e chegar ao seu objetivo final.

Durante as visitas realizadas, foi observada toda a organização do armazém da empresa, local destinado ao estoque dos produtos fabricados, através dessas observações, foram estudadas melhorias para o armazém da empresa.

Segundo Vergara (2016, p. 75), a investigação documental é realizada em documentos conservados no interior de órgãos privados e públicos de qualquer natureza, ou com pessoas: anais, circulares, registros, ofícios, regulamentos, filmes, memorandos, comunicações informais, microfilmes, balancetes, videoteipe, fotografias, dispositivos de armazenagem por meios ópticos, magnéticos e eletrônicos em geral, diários, cartas pessoais e outros.

\subsection{CARACTERIZAÇÕES DA EMPRESA}

A Caloi Norte S/A é uma fábrica que seu ramo principal é o mercado de bicicletas. A história da Caloi Norte SA se iniciou quando o italiano Luigi Caloi desembarcou no Brasil e começou a trilhar seu sonho: ele fundou a Casa Luiz Caloi, que importava bicicletas do mercado europeu.

RC: 85120

Disponível em: https://www.nucleodoconhecimento.com.br/administracao/pdca-para$\underline{\text { maximizar }}$ 
É uma empresa de porte médio, multinacional canadense, com cerca de $32.000 \mathrm{~m}^{2}$ construídos, distribuídos em cinco galpões mais áreas de refeitórios, cozinha, enfermaria e sala de jogos, possui uma filial localizada em São Paulo para área comercial.

Está na memória de gerações e gerações de brasileiros, uma tradição de mais de 120 anos, sejam eles ciclistas profissionais ou não. Uma longa história narrada por bicicletas que fizeram e fazem parte diariamente de muita gente.

O amor por pedalar e saber que significa mais saúde, mobilidade inteligente, esporte e competitividade.

\section{RESULTADOS E DISCUSSÕES}

De acordo com os estudos realizados na etapa do Diagnóstico Organizacional, foi detectado que a empresa Caloi Norte S/A possui pontos fundamentais na área da organização, conforme o Gráfico 01: Medição de desempenho.

Gráfico 01: Medição de desempenho.

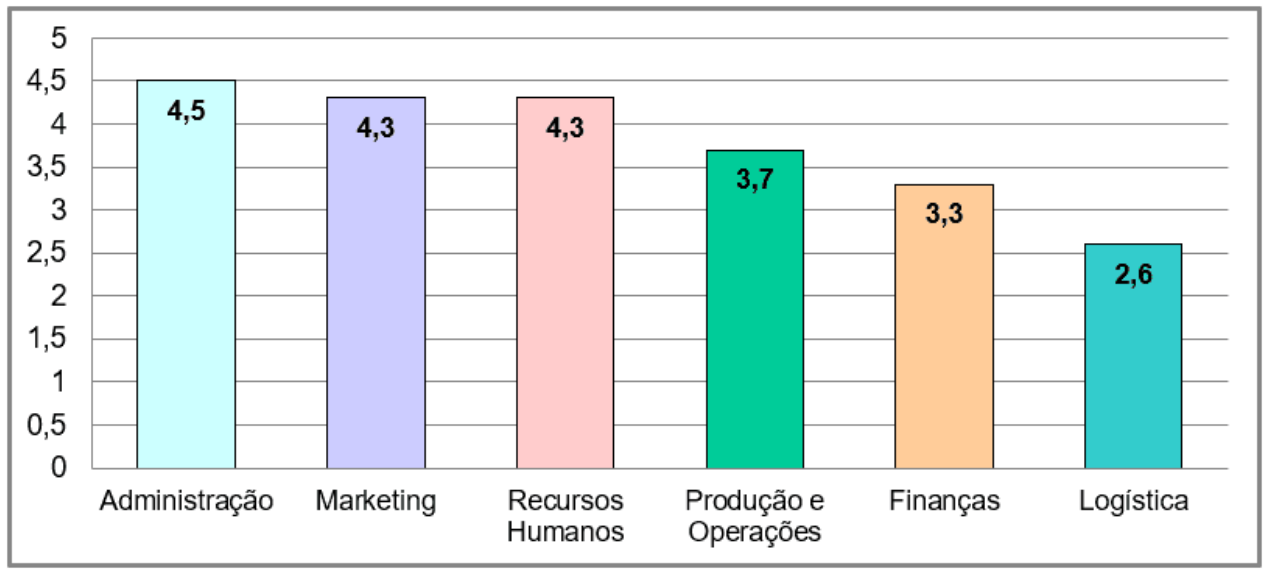

Fonte: Elaborado pelos autores com base na coleta de dados, 2020.

RC: 85120

Disponível em: https://www.nucleodoconhecimento.com.br/administracao/pdca-paramaximizar 
Observa-se que as áreas com melhor desempenho são administração, marketing e recursos humanos, logo, as áreas de produção e operações, finanças são áreas de desempenho médio. Logística com percentual de 2,6 é considerada a área mais crítica, conforme abaixo Quadro 01: Logística.

Quadro 01: Logística.

\begin{tabular}{|c|c|c|c|c|c|c|}
\hline \multicolumn{2}{|r|}{ LOGÍSTICA } & $\begin{array}{l}\text { PONTO } \\
\text { MUITO } \\
\text { FORTE }\end{array}$ & \multirow[t]{2}{*}{$\begin{array}{l}\text { PONTO } \\
\text { FORTE }\end{array}$} & \multirow[t]{2}{*}{$\begin{array}{l}\text { PONTO } \\
\text { MEDIO }\end{array}$} & \multirow{2}{*}{$\begin{array}{c}\text { PONTO } \\
\text { FRACO } \\
x \\
\end{array}$} & \multirow[t]{2}{*}{$\begin{array}{l}\text { PONTO } \\
\text { MUITO } \\
\text { FRACO }\end{array}$} \\
\hline 1 & Processo de ressuprimento & & & & & \\
\hline 2 & Acuradicidade produtos de revenda esta controlada a nivel sistemico & & & & & $x$ \\
\hline 3 & O estoque esta organizado por categorias de produto e ou classes. & & & $\mathrm{x}$ & & \\
\hline 4 & A organização possue equipamentos de movimentação de produtos. & & & $x$ & & \\
\hline 5 & Area de estocagem possuem condiçoes adequadas. & & & $\mathrm{x}$ & & \\
\hline 6 & A empresa possue " Sistema de roteirização para entregas " & & $x$ & & & \\
\hline 7 & Trade-off; Custos (vs) velocidade de entrega & & & $\mathrm{x}$ & & \\
\hline 8 & Controle sobre atrasos de entrega & & $x$ & & & \\
\hline & Logística de retomo: Devoluções & & & $x$ & & \\
\hline & TAL ( $(\Sigma)$ & 0 & 8 & 15 & 2 & 1 \\
\hline & DIA POR GRAU (POR COLUNA) & 0 & 0,8 & 1,5 & 0,2 & 0,1 \\
\hline & SEMPENHO DA ÁREA & & & 2,6 & & \\
\hline
\end{tabular}

Fonte: Elaborado pelos autores com base na coleta de dados, 2020.

Conforme dados coletados na pesquisa de campo, por meio de avaliação de documentos, conversa com equipe Caloi, foi constatado que a área funcional do setor de logística há muitos pontos fracos que necessitam de melhorias para o seu melhor funcionamento operacional.

O quadro logístico demonstra o funcionamento dos processos de estocagem dentro da organização. No quadro é possível detectar as inconformidades presentes nesta área, que necessitam de melhorias para garantir a qualidade na prestação de serviços ao cliente final.

RC: 85120

Disponível em: https://www.nucleodoconhecimento.com.br/administracao/pdca-paramaximizar 
Diante dos resultados, propõem-se que haja uma ação subsequente para solucionar as problemáticas apresentadas, buscando a melhoria contínua no desempenho da área de logística.

Vale ressaltar que há dois pontos mais críticos na área de logística, item 1: Processos de ressuprimento e item 2: Acuracidade dos produtos a nível sistêmico.

\subsection{PLANEJAMENTO DE AÇÕES}

Com intuito de implementar soluções de melhorias, foi desenvolvido uma tabela com ações de atividades para intervir nas ações dos serviços prestados pelos colaboradores.

Quadro 02: Ações Interventivas.

\begin{tabular}{|l|l|l|l|l|l|}
\hline Item & Ação interventiva & Cronologia & Duração & Custo \\
\hline 1. & $\begin{array}{l}\text { Implementação de melhorias no } \\
\text { sistema SAP }\end{array}$ & Março & 12 dias & $R \$$ \\
\hline 2. & $\begin{array}{l}\text { Acuracidade dos produtos auxiliares da } \\
\text { produção a nível sistêmico }\end{array}$ & Abril & 10 dias & $R \$$ \\
\hline 3. & $\begin{array}{l}\text { Automatizar o processo de } \\
\text { apontamento }\end{array}$ & Abril & 15 dias & $\begin{array}{l}\mathrm{R} \$ \\
5.500,00\end{array}$ \\
\hline 4. & $\begin{array}{l}\text { Ressuprimento de material auxiliar } \\
\text { Total }\end{array}$ & Maio & 08 dias & \begin{tabular}{l}
$\mathrm{R} \$$ \\
\hline
\end{tabular} \\
\hline
\end{tabular}

Fonte: Elaborado pelos autores, 2021.

RC: 85120

Disponível em: https://www.nucleodoconhecimento.com.br/administracao/pdca-para$\underline{\text { maximizar }}$ 
As atividades propostas na tabela acima têm como finalidade melhorar e corrigir os pontos considerados críticos na empresa Caloi Norte S.A, com intuito de melhorar o serviço prestado pelo colaborador, tornando os processos eficientes e com qualidade.

\subsection{IMPLEMENTAÇÃO DE MELHORIAS NO SISTEMA SAP}

A implementação da solução proposta promoverá melhorias no processo de gestão do estoque, eliminando possíveis falhas humanas, o melhoramento do fluxo de trabalho, possibilitará melhor controle e diminuirá atrasos no envio de requisições de compra ao setor de Compras.

Após implementação o sistema calculará as necessidades de compras dos insumos utilizados para a produção da empresa, visando o atendimento dos pedidos sem falta nem excesso de estoque, analisando o consumo previsto e o estoque atual, sugerindo então a solicitação de compra.

Quadro 03: 5w2h - Implementação de melhorias no sistema SAP.

\section{Implementação de melhorias no sistema SAP}

\section{O que? Melhoria no Sistema SAP.}

Por quê? Para melhorar a gestão do estoque de materiais auxiliares.

Onde? Na Caloi Norte S/A.

Quando? Última semana de março de 2021.

Quem? Analista do estoque.

Como? Por meio de implantação de sistema MRP no sistema SAP para gerar requisição automática.

Quanto? $R \$ 2.500,00$

Fonte: Elaborado pelos autores, 2021.

RC: 85120

Disponível em: https://www.nucleodoconhecimento.com.br/administracao/pdca-paramaximizar 


\subsection{ACURACIDADE DOS PRODUTOS AUXILIARES DA PRODUÇÃO A NÍVEL SISTÊMICO}

É necessário calcular e definir um estoque de segurança para que o sistema consiga identificar quando deverá ser feita uma nova compra para reposição, portanto a área de estoque e engenharia de produção deverá analisar o consumo e definir uma quantidade mínima e máxima de estocagem dos materiais auxiliares utilizados na produção.

Quadro 04: 5w2h - Acuracidade dos produtos auxiliares da produção a nível sistêmico.

\section{Acuracidade dos produtos auxiliares da produção a nível sistêmico.}

\begin{tabular}{|l|l|}
\hline O que? & Acuracidade no estoque dos materiais auxiliares. \\
\hline Por quê? & Para definir estoque de segurança. \\
\hline Onde? & Na Caloi Norte S/A. \\
\hline Quando? & Segunda semana de Abril de 2021. \\
\hline Quem? & Analista de estoque e engenharia de produção. \\
\hline Como? & Por meio de cálculo de estoque de segurança. \\
\hline Quanto? & $\mathrm{R} \$ 5.500,00$ \\
\hline
\end{tabular}

Fonte: Elaborado pelos autores, 2021.

\subsection{AUTOMATIZAR O PROCESSO DE APONTAMENTO}

Após a definição de estoque, é necessário ajustar no cadastro do material os parâmetros de MRP, colocando os dados de estoque mínimo, máximo e prazo de reposição. 
Com base nessas informações o sistema irá gerar automaticamente uma requisição de compra assim que o material atingir o estoque mínimo.

Quadro 05: 5w2h - Automatizar o processo de apontamento.

\section{Automatizar o processo de apontamento.}

O que? Atualizar dados cadastrais do código do material.

Por quê? Para que o sistema possa efetuar a gestão do estoque gerando a requisição de compra automaticamente

Onde? Na Caloi Norte S/A.

Quando? Última semana de abril de 2021.

Quem? Engenharia de produção.

Como? Através de atualização no sistema SAP.

Quanto? $R \$ 4.800,00$

Fonte: Elaborado pelos autores, 2021.

\subsection{RESSUPRIMENTO DE MATERIAL AUXILIAR}

Ao definir estoque e atualizar as informações no cadastro do código do material, o sistema deverá gerar uma nova requisição de compra assim que determinado material atingir o estoque mínimo informado.

Após requisição ser criada, o sistema sinalizará e enviará a requisição para o comprador seguir com o processo de compras do material de acordo com o lead time para ressuprimento.

Quadro 06: 5w2h - Ressuprimento de material de reposição.

\section{Ressuprimento de material de reposição.}

RC: 85120

Disponível em: https://www.nucleodoconhecimento.com.br/administracao/pdca-paramaximizar 
O que? Teste de geração automática de requisição de compra.

Por quê? Para validar funcionamento do sistema automatizado.

Onde? Na Caloi Norte S/A.

Quando? Segunda semana de Maio de 2021.

Quem? Analista de Estoque e Comprador.

Como? Efetuar teste piloto em determinado grupo de materiais auxiliares. Verificando se o sistema irá sinalizar e criar requisição automática.

Quanto? $\mathrm{R} \$ 3.800,00$

\section{CONSIDERAÇÕES FINAIS}

Diante das ferramentas utilizadas para a realização deste artigo, deve-se destacar que o PDCA é uma ferramenta que tem se mostrado eficaz no ambiente corporativo, possui um conceito simples e objetivo que torna o método aplicável a inúmeras situações, desde reduções substanciais de custos até melhorias de programas em pequena escala (que podem afetar a eficiência da rotina de negócios das pessoas envolvidas).

Com a implementação de melhorias no sistema SAP, acuracidade dos produtos auxiliares da produção a nível sistêmico, automatização do processo de apontamento e ressuprimento de material auxiliar o conhecimento essencial das ferramentas ajudará a melhorar a gestão dos estoques da empresa com o desenvolvimento de tecnologias cada vez mais avançadas, a importância e a demanda por melhorias na empresa.

No entanto, deve-se ressaltar que o objetivo deste artigo é descobrir os defeitos no processo de controle de estoque, e tentar realizar uma investigação teórica das principais ferramentas de gestão necessárias para um bom controle de estoque para $\mathrm{RC}: 85120$

Disponível em: https://www.nucleodoconhecimento.com.br/administracao/pdca-paramaximizar 
evitar a perda de produtos e clientes, evitando a publicidade negativa da empresa e reduzindo os custos relacionados à gestão de estoque.

Ao final do estudo, constatou-se que a empresa não tinha controle suficiente sobre o seu estoque, e seus funcionários realizavam atividades com base em métodos manuais e não científicos. Os entrevistados também descobriram que não tinham conhecimento de ferramentas de gerenciamento de estoque adequadas e fáceis de usar.

No entanto, o estudo de caso mostra que a gestão de estoque é uma parte importante de todas as empresas (independentemente de seu setor), porque as empresas usam os estoques para manter sua situação financeira e desempenham um papel na competição igualitária com as demais empresas.

As ferramentas de qualidade utilizadas neste processo produtivo são muito eficazes na identificação de problemas, formulação de soluções e tomada de decisões, podendo responder aos impactos em tempo hábil, reduzindo assim as perdas por falhas no processo.

Portanto, esta pesquisa atingiu o objetivo proposto, pois reuniu conhecimentos teóricos sobre o tema desenvolvido e procurou colocá-lo em prática de forma efetiva, resolvendo assim o problema identificado como objetivo da pesquisa.

A utilização do ciclo PDCA permite ter um conhecimento mais profundo do plano executado, sua execução, falhas e contramedidas, e aplicá-los de forma correta para obter resultados positivos para o projeto proposto.

RC: 85120

Disponível em: https://www.nucleodoconhecimento.com.br/administracao/pdca-para$\underline{\text { maximizar }}$ 


\section{REFERÊNCIA}

BALLOU, R. H. Logística empresarial: transportes, administração de materiais e distribuição física. Tradução Hugo Yoshizaki, 1 ed. - São Paulo: Atlas, 2012.

BRITO, I. J. SPEJORIM, W. Gestão estratégica de armazenagem - Curitiba: IESDE Brasil S.A., 2012. 320p.

CAMPOS, V. F. Gerenciamento da rotina do trabalho do dia-a-dia. 8. ed. Belo Horizonte: Editora de Desenvolvimento Gerencial, 2004.

CAXITO, F. de A. Produção: fundamentos e processos - 1 ed - Curitiba: IESDE Brasil, 2012. P 112.

CORREA, H. Planejamento, Programação e Controle da Produção. 4Ed. São Paulo: Atlas, 2004.

FERNANDES, K. dos S. Logística: fundamentos e processos - 1 ed. - Curitiba: IESDE Brasil, 2012. P 15.

KAWASE, F. S.; DE PAULA, L. L. A importância do gerenciamento do estoque no setor Supermercadista de pequeno porte na cidade de Lins-SP. Trabalho de Conclusão de Curso apresentado a Faculdade de Tecnologia de Lins Prof. Antônio Seabra, Lins, São Paulo. 2012.

KUEHNE, M. J. Logística de Materiais: uma abordagem complementar Curitiba: 2002.

LAKATOS, E. M.; MARCONI, M. de A. Metodologia científica. 3.ed. São Paulo: Atlas, 2000. 
LAUGENI, F. P.; MARTINS, Petrônio G. Administração da Produção. São Paulo: Saraiva, 2002.

LIBÓRIO, D.; TERRA, L. Metodologia científica - São Paulo: Laureate, 2015. P.15.

MALHOTRA, N. K. et al. Introdução a pesquisa de marketing. São Paulo: Prentice Hall, 2005.

MATTOS, A. D. Planejamento e controle de obras. São Paulo: Pini. 2010.

PRONADOV, C. C. Metodologia do trabalho científico: Métodos e técnicas da pesquisa e do trabalha acadêmico - 2 ed - Nova Hamburgo: Feevale, 2013. P 43.

SANTOS, N. M. dos. et al. A utilização do Ciclo PDCA para melhoria da logística de movimentação - Paraná: Revista Uningá, P 2. 2017. Disponível em: file://C:/Users/Lari/Downloads/2040-13-5906-1-10-20180125.pdf Acesso em: 22/03/2021.

SILVA, L. M. F. da. et al. Proposta de implementação da melhoria método PDCA para a dos processos no controle de estoque: estudo de caso na empresa Ibtech Assistência Técnica. Revista Científica Multidisciplinar Núcleo do Conhecimento. Ano 05, Ed. 11, Vol. 22, pp. 37-56 2020. Disponível em: https://www.nucleodoconhecimento.com.br/administracao/melhoria-metodo-pdca Acesso em: 21/03/2021.

SOUZA, L. C. Avaliação do Processo de Implantação e Utilização do Sistema MRP como Ferramenta para o Planejamento e Controle da Produção: o Caso da LabTest Diagnóstica. 60 f. Monografia (Graduação) - Universidade Federal de Ouro Preto, Minas Gerais, 2003. 
VERGARA, S. C. Projetos e relatórios de pesquisa em administração - 16. Ed. São Paulo: Atlas, 2016.

VIANA, J. J. Administração de Materiais. São Paulo: Atlas, 2000.

Enviado: Abril, 2021.

Aprovado: Maio, 2021.

RC: 85120

Disponível em: https://www.nucleodoconhecimento.com.br/administracao/pdca-paramaximizar 